\title{
A mundialização da sociologia contemporânea: diálogos entre as sociologias na América Latina, na Índia e na China*
}

\author{
José Vicente Tavares dos Santos, \\ Alex Niche Teixeira, \\ Rochele Fellini Fachinetto \& \\ Vitor Eduardo Alessandri Ribeiro**
}

Resumo: O texto propõe uma reflexão acerca das contribuições que a sociologia na América Latina, China e Índia podem oferecer ao pensamento social na etapa da mundialização das conflitualidades sociais. Propomos uma interlocução múltipla, que tenha como base a historicidade dos diversos processos de construção da sociologia, evidenciando que os conceitos, assim como os percursos de construção do conhecimento, possuem uma história que não é universal nem homogênea, mas refletem as lutas sociais, as contradições locais e contextos heterogêneos. Essa reconstrução aproxima caminhos epistemológicos da sociologia na América Latina, China e Índia. Ao problematizar tal percurso a partir de uma "epistemologia do Sul", nos termos de Boaventura de Sousa Santos, colocamos em diálogo a diversidade das práticas e dos saberes mundiais sob a perspectiva de um diálogo horizontal entre estes conhecimentos.

Palavras-chave: epistemologia, mundialização, conflitualidades, sociologia, América Latina, sociologia latino-americana, China, sociologia chinesa, Índia, sociologia indiana, historicidade.

\section{Introdução}

A sociologia tem expressado as profundas transformações das sociedades contemporâneas, acompanhando a emergência de novas questões sociais, as quais produzem significativo impacto global. Tais desafios, e seus impactos nas diferentes realidades sociais (locais, regionais e globais), devem ser incorporados às tarefas da sociologia em todo o mundo.

A Era da Mundialização das Conflitualidades, iniciada em 1991, pode ser compreendida como o fim da ordem global bipolar, era na qual as sociedades experimentam o surgimento de novos tipos de violências e conflitos (Hobsbawm, 1994; Arrighi, 2007; Tavares dos Santos, 2009).

A reflexão sociológica latino-americana, valendo-se de seu característico internacionalismo, seu hibridismo, sua abordagem crítica dos processos e dos conflitos e mantendo o compromisso social por parte dos sociólogos, expande o escopo de sua interlocução: busca ampliar seu diálogo internacional rumo a novas fronteiras, em-
* Uma primeira versão deste texto foi apresentada no GT26

- Pensamento social latino-americano da Associação Nacional de Pós-Graduação e Pesquisa em Ciências Sociais (Anpocs), em outubro de 2012.

** José Vicente Tavares dos Santos é professor titular do Departamento e do Programa de Pós-Graduação em Sociologia da Universidade Federal do Rio Grande do Sul. Membro do Conselho Universitário da UFRGS. Pesquisador do CNPq (nível I-A), diretor do Instituto Latino-Americano de Estudos Avançados (Ilea) da UFRGS, coordenador do Grupo de Pesquisa Violência e

Cidadania, desde 1995.

Alex Niche Teixeira é professor adjunto do Departamento de Sociologia e do Programa de Pós-Graduação em Sociologia da Universidade Federal do Rio Grande do Sul (UFRGS). Pesquisador associado ao Instituto Nacional de Ciência e Tecnologia em Violência, Democracia e Segurança Cidadã CNPq e do Grupo de 
Pesquisa Violência e Cidadania - UFRGS/ CNPq.

Rochele Fellini

Fachinetto é

professora adjunta do Departamento

de Sociologia/

UFRGS; pesquisadora

do Grupo de

Pesquisa Violência e

Cidadania/UFRGS.

Vítor Eduardo

Alessandri Ribeiro é

mestre e doutorando

em sociologia

no Programa de

Pós-Graduação

em Sociologia da

Universidade Federal

do Rio Grande do

Sul (PPGS-UFRGS) e

membro do Grupo

de Pesquisa em

Violência e Cidadania

(GPVC).

Email do Grupo de

Pesquisa Violência

e Cidadania/

UFRGS: <http://

www.ufrgs.br/

violenciaecidadania/

contato>. penhando-se numa abordagem compreensiva dos complexos dilemas trazidos pela emergência de novas questões sociais em âmbito mundial.

Podemos identificar seis períodos na sociologia da América Latina e do Caribe:

1. a herança intelectual da sociologia (século XIX até início do século $X X)$;

2. a sociologia da cátedra (1890-1950);

3. o período da "sociologia científica" e a configuração da "sociologia crítica" (1950-1973);

4. a crise institucional, a consolidação da "sociologia crítica" e a diversificação da sociologia (1973-1983);

5. a sociologia do autoritarismo, da democracia e da exclusão (19832000);

6. atualmente, vivenciamos o sexto período desta longa história intelectual: a consolidação institucional e a mundialização da sociologia.

Este período representa uma nova etapa da internacionalização da sociologia da América Latina, o que nos leva a enunciar um conjunto de questões bastante pertinentes que orientam nosso esforço:

- Qual o papel que a sociologia na América Latina pode desempenhar na etapa de mundialização de conflitualidades sociais?

- Como desenvolver uma "interlocução múltipla" em um espaço-tempo mundial, mirando múltiplas sociologias, do Norte e do Sul, do Ocidente e do Oriente?

- Como expressar a diversidade social e cultural latino-americana, chinesa e indiana em novas questões sociais mundiais?

Adiante, analisaremos a periodização da sociologia na Índia e na China. Antes, cabe problematizar, desde a América Latina, as questões sociológicas mundiais.

\section{A sociologia contemporânea na América-Latina}

A contemporaneidade da sociologia na América Latina salienta alguns problemas sociológicos mundiais, os quais deverão ser respondidos em uma perspectiva que abarque o diálogo entre outras sociologias: 
1. historicidade do conhecimento, com processos não lineares;

2. perspectiva de uma ecologia dos saberes, criticando a colonialidade dos saberes;

3. mundialização do conhecimento, marcado pela diversidade, diferenciação e transculturação;

4. nova morfologia do social, com agrupamento de classe social combinados com relações de gênero, relações raciais, grupos etários;

5. relações entre poderes, saberes, culturas e fluxos de informação;

6. novas questões sociais mundiais.

Diante de tais questões, temos um novo desafio intelectual: como construir as "epistemologias do Sul" não apenas na América Latina? Ao propor uma interlocução múltipla que tenha como base a historicidade dos diversos processos de construção da sociologia, a abordagem coloca em diálogo os caminhos epistemológicos da sociologia na América Latina, Índia e China.

Pretendemos problematizar tal percurso a partir das "epistemologias do Sul", a qual busca reconhecer a diversidade das práticas e saberes do mundo, sob a perspectiva de um diálogo horizontal entre estes conhecimentos (Sousa Santos \& Meneses, 2010). Tal perspectiva busca evidenciar que os conceitos, assim como os percursos de construção do conhecimento, têm uma história que não é universal nem homogênea, mas que reflete lutas sociais, contradições e contextos heterogêneos. Trata-se de reconhecer que não fazemos parte de uma história única, pois houve um silenciar de uma multiplicidade de práticas e contextos sociais, produzindo uma homogeneização dos múltiplos lugares de enunciação de saberes.

Boaventura de Sousa Santos e Paula Meneses salientam que este processo de silenciamento tornou possível a imposição de uma epistemologia dominante que não reconhece outras práticas sociais e formas de saber. Parte da premissa de que qualquer conhecimento válido é sempre contextual e de que as experiências sociais são constituídas por vários conhecimentos. Os autores questionam:

[por que] nos últimos dois séculos, dominou uma epistemologia que eliminou da reflexão epistemológica o contexto cultural e político da produção e da reprodução do conhecimento? (Sousa Santos \& Meneses, 2010: 9-10).

Indica sobretudo o processo de descontextualização da produção de conhecimento de uma epistemologia que acabou impondo-se nos mais variados contextos sociais, 
como se fora produto de um único espaço-tempo, estabelecendo determinados modos e contextos da produção de conhecimentos como mais válidos ou mais reconhecidos do que outros.

O contexto de construção dessa epistemologia dominante não poderá ser compreendido sem considerar a incidência de dois processos interligados: o capitalismo e o colonialismo, este entendido não apenas em suas dimensões políticas, mas como forma de dominação epistemológica.

Para além de suas dimensões econômicas e políticas, observam-se múltiplas formas de dominação associadas a estes processos, que adentram à subjetividade e ao modo de produzir conhecimento dos contextos colonizados (Sousa Santos, 2000), impondo a visão de uma única história - a história dos dominadores, dos colonizadores. O colonialismo - na leitura do autor - constitui-se como forma de dominação epistemológica que acarreta a supressão de múltiplas formas de saber que foram sendo construídas ao longo da história.

Ao considerar que "toda prática social produz e reproduz conhecimento" expande sua análise não apenas aos saberes, mas às próprias práticas sociais submetidas a este processo de imposição, configurado no âmbito das relações coloniais no espaço-mundo (Sousa Santos \& Meneses, 2010: 9), parte de duas ideias principais: não há epistemologias neutras; a reflexão epistemológica deve incidir nas práticas de conhecimento e nos seus impactos em outras práticas sociais (Sousa Santos \& Meneses, 2010: 7).

Tornar-se inteligível traduz uma ideia de existência: é como um passar a existir ou, ao contrário, permanecer numa "não existência". A constituição desta epistemologia dominante está assentada numa dupla diferença: a diferença cultural do mundo moderno cristão ocidental e a diferença política do colonialismo e do capitalismo.

Said traz para o debate a construção epistemológica do Oriente pelo Ocidente, na qual este acaba situando aquele como o lugar do exótico, do diferente, do "outro" (Said, 2004). Tal operação realiza-se mediante um processo de "comparação" a partir de um ponto central, que possibilita a identificação do outro como algo diferente.

A grande contribuição da corrente pós-colonial, cujos fundamentos tiveram origem na década de 1980, é assumir que toda enunciação vem de algum lugar e isso explicita uma posição política, demanda um posicionamento, já que os discursos expressam algo sobre o lugar do qual se fala. Os estudos pós-coloniais fazem uma importante crítica ao conhecimento científico que privilegia um modelo, um centro 
do qual partem os discursos que acabam construindo percepções e representações acerca daquilo que não está nesse centro, como o próprio Oriente, por exemplo.

Essa construção de um mundo ocidental cristão em oposição ao lugar do exótico, do "outro", reivindica uma pretensão de universalidade que veio a se plasmar na ciência moderna: resultado de uma intervenção epistemológica que só foi possível com base na força com que se impôs a intervenção política, econômica e militar do colonialismo e do capitalismo moderno aos povos e culturas não ocidentais e não cristãs (Sousa Santos \& Meneses, 2010: 10).

Este processo de colonização do saber (Quijano, 2005) tentou homogeneizar o mundo e desacreditar tanto os conhecimentos como as práticas sociais que o engendram, configurando um processo de aniquilamento das diferenças culturais, bem como o desperdício das mais variadas experiências sociais.

Em alternativa à epistemologia dominante, Boaventura de Sousa Santos situa-nos no debate acerca das epistemologias do Sul, propondo uma ecologia dos saberes:

As epistemologias do Sul são o conjunto de intervenções epistemológicas que denunciam essa supressão, valorizam os saberes que resistiram com êxito e investigam as condições de um diálogo horizontal entre conhecimentos (Sousa Santos \& Meneses, 2010: 13).

O "Sul" é concebido como metáfora que busca evidenciar as práticas e saberes que foram silenciados historicamente pelo capitalismo em sua relação colonial com o mundo. Boaventura não propõe apenas uma "sobreposição com o Sul geográfico", tendo em vista que os processos que expressam as consequências do capitalismo e do colonialismo pelo mundo são muito desiguais e, portanto, há situações de opressão e dominação no Norte, bem como, pequenas "Europas" e elites locais que se beneficiaram da dominação capitalista no Sul.

Em obra recente, o mesmo autor salienta a importância de se desenvolver uma sociologia das ausências e uma sociologia das emergências, entendendo aquela como as dimensões da sociedade que foram obscurecidas pelo pensamento eurocêntrico e esta como as novas questões que se colocam com vigor nas sociedades do Sul (Sousa Santos, 2006).

Traz, em seu conjunto, conceitos importantes para esta tentativa de comparação entre tradições sociológicas de três continentes. Estamos indicando uma ausência - a falta de comunicação entre tradições sociológicas do Sul - e uma emergência: o necessário diálogo em devir de tais experiências intelectuais. 


\section{O necessário diálogo entre as sociologias latino-americana, indiana e chinesa}

O estabelecimento de diálogos com a sociologia indiana e a sociologia chinesa torna-se um novo patamar da internacionalização da sociologia crítica latino-americana. Ciente das dificuldades antepostas pelas diferenças culturais e linguísticas a serem superadas num esforço de grupo, este texto é um primeiro passo de um amplo projeto que pretende fomentar o diálogo entre as sociologias latino-americana, chinesa e indiana, bem como refletir sobre os caminhos de outra sociologia mundial no século XXI.

Nestas sociedades de histórias diversas e temporalidades distintas, as ciências sociais são importantes aliadas para o enfrentamento de desafios ao desenvolvimento econômico, social e humano.

1. Danielle Elisseeff (2011): "China has fascinated Europe for centuries because its culture, philosophy and social systems are so different to our own. Yet its most essential notion remains unfamiliar: transformation. This notion is base on the principle that life - of which death is just one aspect - is expressed through incessant changes. This cycle is an invitation for an excursion through the many representations of this idea-images that try to give a shape to that which, in fact, is devoid of any lasting form". Ver ainda Yves Chevrier, Alain Roux \& Xiaohong Xiao-Planes (2010).

\section{Para}

aprofundamento e mais detalhes sobre a história da China, ver: Patrícia Buckley Ebrey (2010).
Guardadas as enormes diferenças culturais e linguísticas, Brasil, China e Índia guardam semelhanças em importantes aspectos naturais e humanos: com grandes diversidades de domínios morfoclimáticos e com a presença de imensas bacias hídricas - muito relevantes para o desenvolvimento histórico -, são países de gigantescas dimensões territoriais, de vastas populações e imensos mercados internos. Tanto suas especificidades como os traços comuns são responsáveis por conformar realidades ímpares, as quais, diante da emergência de novas questões sociais na contemporaneidade, enfrentam enormes desafios sociais. Tais desafios fornecem um campo riquíssimo à investigação sociológica.

\section{A sociologia na China}

A China, no transcurso de sua longa história, testemunhou significativas transformações ${ }^{1}$ políticas, econômicas e sociais ${ }^{2}$. Do período moderno à contemporaneidade, desafios em suas relações com o mundo externo a trouxeram à necessidade de mudanças mais profundas (Fenby, 2008).

A China experimentou, no pós-Segunda Guerra Mundial, um período de grande penúria, mas logrou estabelecer, em curto espaço de tempo, as bases iniciais da urbanização e da industrialização. Durante o período de 30 anos, a partir da Revolução Socialista de 1949, a China elaborou um sistema político totalitário típico, com a apropriação da economia pelo Estado e com a centralização do planejamento. A partir das reformas introduzidas por Deng Xiaoping, iniciadas em 1978, o país inicia uma trajetória que o conduz para o crescimento econômico e sua inserção soberana no rol das grandes nações (Jabbour, 2010: 68). 
A transição social experimentada pela China no decurso das transformações realizadas é inédita pela imensidão da população envolvida, pela vitalidade do processo e pela profundidade das mutações que se produzem em sincronia: de uma sociedade tradicional para uma sociedade "moderna"; de uma sociedade rural para uma sociedade urbana; e de uma sociedade planificada para uma sociedade sob regulação de mecanismos de eficiência e de preços. As mudanças sofridas pela China nos últimos 30 anos equivalem às transformações na história da modernização mundial de 1840 até os tempos atuais (Li Peilin, Guo Yuhua \& Liu Shiding, 2008: 84), visto que, na China, todas as etapas são mais curtas e ocorrem em um mesmo tempo histórico. A sincronicidade e a profundidade dos impactos daquelas mudanças na sociedade chinesa levaram a um ganho de vigor na produção de pesquisas sociais.

Segundo o professor Huang Ping ${ }^{3}$, o início da produção sociológica na China remonta aos fins do século XIX e princípios do século XX, quando uma primeira geração de estudiosos e acadêmicos chineses realizava intercâmbios acadêmicos em países ocidentais, majoritariamente Reino Unido e Estados Unidos. No ano de 1952, a prática da sociologia foi proibida pelo governo chinês, mas continuou a ser praticada ainda que clandestinamente. Durante os anos da Revolução Cultural (de 1966 a 1976) as ciências sociais foram quase extintas e eram raramente ensinadas nos ambientes acadêmicos do país.

Após o início do processo de abertura pós-1978, as ciências sociais foram resgatadas e receberam, segundo o professor Ping, o mandato oficial para apoiar o processo de reforma ${ }^{4}$. A partir de 1979, a China engendrou esforços para liberar a economia da iniciativa estatal exclusiva e reorganizá-la segundo os princípios da regulação através do mercado. Essas reformas permitiram a edificação de um sistema econômico de "socialismo de mercado" e deram lugar ao aumento sem precedentes da riqueza nacional (Shen Yuan, 2008: 299-305).

A sociologia recebeu a incumbência de formar especialistas que pudessem auxiliar e apoiar o Estado na formação de políticas públicas, a partir da aprendizagem de experiências no exterior, por isso passou a incrementar a capacidade nacional de produção de pesquisas em ciências sociais através de uma agenda voltada ao desenvolvimento, o que foi possível graças à capacidade crescente de financiar estudos (Li Peilin, Guo Yuhua \& Liu Shiding, 2008: 84). A preocupação era a realização de pesquisas para a compreensão das dificuldades produzidas pelo crescimento econômico; o incremento de intercâmbios internacionais foi fundamental.

No primeiro momento, ao longo da década de 1980, as problemáticas trazidas pelos estudos sociológicos chineses enfocavam muitos dos desafios sociais impostos pela rápida modernização. Investigações em temas como as unidades produtivas

\author{
3. Doutor em \\ sociologia pela \\ London School of \\ Economics (LSE), \\ é diretor geral do \\ Instituto de Estudos \\ Americanos da \\ Academia Chinesa \\ de Ciências Sociais \\ e vice-presidente do \\ Instituo Internacional \\ de Sociologia (IIS), \\ além de editor \\ geral de grandes \\ publicações como \\ Current Sociology \\ e Comparative \\ Sociology. \\ 4. Ver: <http://www. \\ aurore-sciences. \\ org/fr/publication- \\ show/172>. \\ Acessado em: Jun. \\ 2013).
}


rurais, o superpovoamento das cidades, os problemas de poluição ambiental, o déficit de infraestrutura urbana, estudos de famílias, a evolução da situação matrimonial, estudos institucionais, estudos de governança e de temas de segurança pública tornaram-se recorrentes. Estudos produzidos neste período foram orientados à dimensão empírica, à coleta primária de dados, com menor ênfase à elaboração epistemológica.

Lacunas nesse sentido foram sendo preenchidas paulatinamente. A sociologia chinesa experimentou um sensível progresso principalmente a partir do começo da década de 1990. A pesquisa social passou a enfocar não mais apenas os desafios sociais do país, mas também as deficiências teóricas do conhecimento científico então produzido. Houve, nesta fase, significativos avanços em relação à problemática de construção de teorias e adoção de normas científicas compartilhadas com centros de produção de conhecimento social em vários países do mundo. A sociologia chinesa ganha força enquanto voz reconhecida para o estabelecimento de diálogos científicos.

Durante os anos 2000, estudos acadêmicos sobre as tradições clássicas chinesas foram reintroduzidos nos espaços acadêmicos e captaram as atenções e o interesse de um número crescente de estudantes. Atualmente muitos estudos estão em curso perseguindo as seguintes temáticas: a rápida urbanização, a massiva migração rural-urbana, a reforma do sistema previdenciário, a ampliação de prestação de serviços públicos de saúde, a universalização da educação, o acesso à moradia e a reforma do sistema jurídico. São abordagens informadas pela noção de "transição social", nova postura aceita em função da compreensão de uma sociedade em processo de complexificação e de mutação acelerada (Li Peilin, Guo Yuhua \& Liu Shiding, 2008: 83).

Os atuais trabalhos dos sociólogos chineses contribuem efetivamente para a construção de uma agenda internacional para a disciplina sociológica, pois, através da análise de uma multiplicidade de práticas, evidenciam a diversidade de saberes num mundo de contextos heterogêneos e repleto de contradições. Compartilham, no cenário internacional, de objetos de investigação, conceitos teóricos, metodologias em profícuo diálogo com pesquisas sociais produzidas em diferentes países, num significativo e enriquecedor intercâmbio de interpretações sociológicas (Chen Yingying, 2008: 411).

A sociologia chinesa goza atualmente de amplo reconhecimento mundial. Nacionalmente, engaja-se também no processo de produção de conhecimento, na formulação de políticas públicas em diferentes níveis, em resposta aos desafios que lhes são oferecidos (Li Peilin, Guo Yuhua \& Liu Shiding, 2008). Evidentemente, outras disciplinas participam desta tarefa, cabendo aqui apenas salientarmos a contribuição da sociologia. 
O crescente número de centros acadêmicos dedicados à sociologia, o incremento do número de pesquisadores e, certamente, da qualidade das publicações são importantes indicadores deste florescimento da sociologia chinesa nos últimos 30 anos. Os principais atores deste processo são a Academia Chinesa de Ciências Sociais (Chinese Academy of Social Sciences - Cass), o Centro Nacional de Pesquisa em Humanidades e em Ciências Sociais e o Instituto da América Latina, que sedia o Centro de Estudos Brasileiros. Para o Brasil, é particularmente importante o interesse que a Cass apresenta pela experiência brasileira 5 .

A Cass foi instituída em 1977, a partir do Departamento de Filosofia e Ciências Sociais da Academia Chinesa de Ciências. Possui atualmente 37 institutos e mais de 150 centros de pesquisa e escolas de graduação que desempenham atividades que abrangem 260 subdisciplinas.

Ao tomar como base os trabalhos do Instituto de Sociologia da Academia Chinesa de Ciências Sociais, disponíveis também em importante livro publicado em Paris (Roulleau-Berger et alii, 2008), podemos identificar as seguintes linhas de pesquisa na sociologia chinesa contemporânea:

1. estudo das transformações sociais;

2. conceito de "sociologia da transição";

3. conflitos agrários e a migração rural-urbana;

4. transformações do trabalho, efeitos das novas tecnologias, as "cidades fragmentadas" e os trabalhadores migrantes;

5. sociologia da juventude

6. a violência social difusa e os meios de prevenir a violência;

7. o sistema de justiça criminal e o modelo de controle social;

8. modos de policiamento comunitário;

9. construção da sociedade com respeito à cidadania e à diversidade social em um novo nível do processo civilizatório.

Ao expressar alguns pontos importantes sobre a sociologia chinesa segundo alguns de seus sociólogos ${ }^{7}$, algumas propostas de mudanças são elaboradas como meios de fazer frente aos efeitos da transformação social recente na China, entre elas:

1. permitir o acesso a uma informação aberta, transparente e completa, sempre objetivas;

2. colocar em concertação as reivindicações relacionadas a interesses particulares divergentes;
5. O professor José Vicente Tavares dos Santos professor titular do Departamento de Sociologia do Instituto de Filosofia e Ciências Humanas da UFRGS, esteve presente no XXXVI Congresso Mundial de Sociologia da ISA, em julho de 2004, em Beijing, China, onde coordenou a Sessão 93, intitulada "The age of insecurity: social conflicts, violence and the building of peace in everyday life in post modern societies".

O interesse pela aproximação entre as sociologias brasileira e chinesa também ficou evidente com a participação de Tavares dos Santos na conferência de celebração do trigésimo aniversário do Instituto de Sociologia da Academia de Ciências Sociais da China com o trabalho intitulado "BRIC sociology: globalization and social development", em abril de 2010 em Beijing. Desta mesma conferência participou o Professor Thomas Patrick Dwyer, que presidiu a Sociedade Brasileira de Sociologia (SBS) de 2005 a 2009, e é atualmente membro do Comitê Executivo da International Sociological Association (ISA), com mandato de 2010 a 2014. Ainda em 2010, em Gotemburgo, na Suécia, Tavares dos Santos participou do XVII World Congress 
of Sociology. Violence, Peace and War, participação que resultou na publicação intitulada The dialogue between criminology and the south sociology of violence: the policing crisis and alternatives, publicada em Michael Burawoy, Mau-Kuei Chang, \& Michelle Fei-Yu Hsieh (2010). Além disso, atesta-se, à profusão, maiores contatos de aproximação entre as sociologias do Sul com a realização do evento Sociologias do Século XXI, em comemoração aos 40 anos do Programa de Pós-Graduação em Sociologia da Universidade Federal do Rio Grande do Sul, evento que contou com a participação da professora Li Chunling, do Instituto de Estudos LatinoAmericanos da Academia Chinesa de Ciências Sociais, além de outros professores da África do Sul e da Índia.

\section{6. Área cujo} desenvolvimento o professor Thomas Patrick Dwyer tem oferecido importante contribuição. Ver: Tom Dwyer (2007; 2011; 2012).

\section{São tomadas} algumas opiniões a partir de formulações de sociólogos da Universidade Tsinghua: <http:// www.tsinghua. edu.cn/publish/ Socen/2745/>.
3. estabelecer um sistema de participação social e de expressão dos cidadãos;
4. garantir meios de pressão também para os grupos vulneráveis;
5. estabelecer dispositivos de consulta e de negociação, buscando a autorregulação social;

6. instaurar o dispositivos de arbitragem e de negociação.

O diálogo entre as sociologias chinesa e brasileira, no caso específico da planificação e das políticas sociais, possibilita iniciar o incremento da aproximação e construir outra sociologia mundial no século XXI, orientada pelas perspectivas da transição e da transformação, tanto no social como no saber, a fim de contribuir para a construção da cidadania mundial.

\section{A SOCIOLOGIA CHINESA, TEMAS E PESQUISAS}

\begin{tabular}{|c|c|}
\hline Temas & Estudos \\
\hline Segurança social & $\begin{array}{l}\text { Mecanismos inovadores voltados às comunidades e de apoio aos desfavorecidos. } \\
\text { Segurança e Estado de bem-estar social. } \\
\text { Segurança social. } \\
\text { Políticas sociais no processo de implantação de um sistema de mercado. }\end{array}$ \\
\hline Inovação & Mudança institucional e processos sociais inovadores. \\
\hline Pobreza & $\begin{array}{l}\text { Pobreza e vida em comunidade das minorias. } \\
\text { Pobreza urbana. }\end{array}$ \\
\hline Desenvolvimento & Sistemas e modelos de previsão sobre o desenvolvimento social. \\
\hline Migração & $\begin{array}{l}\text { Migração rural } \mapsto \text { urbana em períodos de reforma. } \\
\text { Migração rural } \mapsto \text { urbana contemporânea. }\end{array}$ \\
\hline Imaginário & Psicologia social durante o período de transição. \\
\hline Trabalho & $\begin{array}{l}\text { Estudos de unidades de trabalho e desenvolvimento social. } \\
\text { Empresas estatais e organizações não estatais. } \\
\text { Realocação profissional em regiões de cinturão industrial. }\end{array}$ \\
\hline Organizações sociais & Organizações civis e reconstrução comunitária. \\
\hline Pensamento social & Escolas ocidentais de pensamento e pensamento sociológico. \\
\hline Urbano & Desenvolvimento de pequenas cidades na China. \\
\hline Indicadores sociais & Estudos econômicos e sociais de pequenos municípios. \\
\hline Família & $\begin{array}{l}\text { Estudos de famílias em áreas urbanas e rurais. } \\
\text { Atuais tendências e estratégias para cuidados com idosos em áreas rurais e urbanas. }\end{array}$ \\
\hline Estrutura social & $\begin{array}{l}\text { Condição social presente e tendências futuras. } \\
\text { Estrutura social e desenvolvimento de mercado. } \\
\text { Estruturas sociais e estratificação social contemporâneas. } \\
\text { Estratificação e mobilidade social. }\end{array}$ \\
\hline Conflitualidade & Contradições de interesses entre indivíduos. \\
\hline Juventude & Valores da juventude chinesa. \\
\hline
\end{tabular}

Fonte: Institut of Sociology - Chinese Academy Social Sciences. Compilação dos autores. 


\section{A sociologia na Índia}

Para este escorço, destacaremos o processo de dependência que o imperialismo inglês exerceu sobre a sociedade indiana, lembrando a desindustrialização ocorrida ainda no século XIX (Baran, 1972). Da herança colonial ficou uma administração federativa e um sistema político parlamentarista, com uma administração pública ampla, em interação "com o sistema social, com a esfera política e com os interesses político-eleitorais dos parlamentares" (Lopez, 2008: 69-92).

A crítica às formas de dominação capitalistas e coloniais, sobretudo em sua dimensão epistemológica, contribui para compreender a sociologia indiana, pois situa os processos coloniais na reconstrução do pensamento sociológico do país.

Ao apresentar uma reconstrução histórica da sociologia indiana, Ishwar Modi (2010) argumenta que essa passa por um momento crítico, tendo em vista que está ainda dominada pela mudança dos paradigmas do Ocidente. A sociologia indiana ainda não completou sua própria contribuição à teoria social e ao desenvolvimento conceitual.

A emergência das ciências sociais pode ser pensada como consequência do processo de colonização que se estabeleceu no país. Os administradores britânicos procuraram conduzir diversas pesquisas, tanto com enfoque qualitativo como quantitativo, a fim de conhecer os limites do seu controle (Lardinois, 2009).

Segundo Alatas (2006: 8), há uma "sobredependência das contribuições do pensamento ocidental", que se deu não apenas pela imposição colonial, mas, sobretudo, pelo que se entende como uma "aceitação" até mesmo com certo "entusiasmo" das abordagens e dos conceitos utilizados para pensar realidades muito diversas daquela da Índia.

Esta mudança nos estudos sociológicos deveria ser levada a cabo por escolas locais orientadas pelos problemas relativos a estes contextos sociais, sendo capazes de desenvolver e aplicar de forma independente conceitos que tenham relevância para as questões do país e suas regiões. É preciso contextualizar os conceitos que são amplamente utilizados para a análise das diversas sociedades, como, por exemplo, sanções, classe social, estratificação, mobilidade social, cultura, entre outros. São conceitos universais, mas suas manifestações empíricas podem ser muito diversas e precisam ser contextualizadas e problematizadas. Fundamenta sua crítica a falta de um pensamento autônomo às ciências sociais não ocidentais, o que acaba, muitas vezes, reproduzindo conceitos centrais da sociologia de forma não contextualizada no tempo e no espaço. 
A sociedade indiana foi constituída por diferentes processos que atuaram conjuntamente: o colonialismo, o nacionalismo e a constituição do Estado moderno indiano. Compreender essa sociedade implica considerar como estes processos se configuraram na história da Índia (Oommen, 1988: 309).

Este tema também é abordado ao se focar a diferença entre os estudos rurais e urbanos: alguns trabalhos analisam formas de produção artesanal que não podem ser explicadas nos termos da acumulação capitalista. Portanto, há limites na utilização de categorias sociológicas universalizantes sem situá-las e repensá-las nos vários contextos sociais (Patel \& Deb, 2006: 454).

O desenvolvimento da sociologia indiana não pode ser compreendido de forma apartada das diversas fases históricas da nação. A emergência da sociologia como disciplina formal deu-se na Índia em 1919 e coincidiu com algumas fases críticas da história do país (Modi, 2010: 316). Naquele contexto, Gandhi já havia retornado da África do Sul e várias medidas de reconstrução do país estavam sendo tomadas como consequência do período pós-Primeira Guerra Mundial. Sua marcante presença inspirou o pioneirismo de muitos sociólogos, dedicados ao estudo do homem comum.

A pesquisa sociológica na Índia foi iniciada antes mesmo do advento da sociologia formal pelos administradores britânicos. Entretanto, Modi (2010: 316-317) faz uma crítica a estas primeiras abordagens desenvolvidas ainda no período pré-Independência indiana. Na sua concepção, essas análises não produziram uma compreensão apropriada da realidade do país, pois se fundamentavam numa inadequada e imprecisa apreensão dos costumes locais e tradições e estavam marcadas por julgamentos acerca da cultura e dos diferentes arranjos institucionais. Para ele,

8. Yogendra Singh nasceu em 1932, numa pequena vila chamada Chowkhar, perto da fronteira com o Nepal, cidade de sistema econômico basicamente feudal, e fez sua educação primária em escolas locais. Em sua obra, analisou a tradição e a mudança, a fluidez das estruturas e da formação de realidades sociais, salientando a inadequação de velhas categorias (cf. Modi, 2012: 8). os administradores coloniais fizeram uso da sociologia para poder executar mais "suavemente" a sua administração e dominação colonial.

Na sua crítica a estes estudos, Yogendra $\operatorname{Singh}^{8}$ salienta uma visão da realidade social mecanicista, segmentaria e instrumental, constituindo um típico paradigma colonial, oferecendo uma imagem fraturada da sociedade indiana. Menciona alguns exemplos: o exagero de elementos que marcavam as clivagens e segmentações sociais; o preconceito presente nas análises dos sociólogos ocidentais que enfatizavam interpretações negativas acerca da realidade indiana e apontavam como possível "solução" para o problema o caminho da cristianização.

A forma dos "ocidentais" pensarem o tema da religião expressa essa forma mecanicista e caricatural de analisar a sociedade indiana (Modi, 2010). Enquanto, na constituição do pensamento ocidental, busca-se a secularização do pensamento, 
na Índia a religião não é vista como algo que obstaculiza o pensamento livre. Portanto, olhar a Índia sob este viés constitui uma forma inadequada de caracterizá-la.

Ao retomar a constituição histórica do pensamento sociológico na Índia, o autor divide os temas e o desenvolvimento da sociologia indiana de acordo com seus diferentes períodos históricos. Destaca, inicialmente, o período pré-Independência, no qual situa o desenvolvimento das disciplinas sociologia e antropologia social, as quais tiveram seu início em duas cidades que, simbolicamente, representam o colonialismo: Bombaim e Calcutá. A sociologia tinha um papel secundário neste período e os centros de ciências sociais iniciavam suas atividades com disciplinas de economia.

Como referências notáveis na produção de conhecimento neste período, Modi (2010: 318) destaca Seal e Sarkar, inspirados no Movimento Nacional Indiano, como os pioneiros nos estudos sobre etnicidade, religião e cultura. G. S. Ghurye desenvolveu estudos sobre família, estrutura de parentesco, casamento, grupos étnicos, destacando-se seu estudo sobre os hábitos sexuais da classe média em Bombaim, introduzindo o empirismo na sociologia indiana (cf. Modi, 2010: 318). Em Calcutá, destaca-se Radhakamal Mukherjee, que começou a formação em economia, desenvolvendo como foco a economia rural e os problemas da terra (1926-1927), populacionais (1938) e temas ligados às condições da classe trabalhadora (1945).

Modi (2010) destaca, ainda, a atuação de Chattopadhyay, antropólogo formado em Cambridge, que conduziu estudos de survey revelando as condições de vida dos camponeses e da classe trabalhadora em Bengali. Seus trabalhos sobre o sistema social indiano e suas instituições sociais no período pré-Independência foram influenciados pelo estilo e conteúdo dos trabalhos etnográficos produzidos pelas escolas britânicas no período colonial.

Os principais temas de estudo desenvolvidos neste período versavam sobre castas, família, casamento, parentesco, estratificação social, comunidades tribais, sociedade urbana e rural. Um dos centros que mais contribuiu para o crescimento da sociologia neste período foi Lucknow. Nessa escola, destaca-se a atuação de Mukerji, que se dedicou ao estudo da música e das artes como criação peculiar da cultura indiana.

No período pós-Independência, houve uma fase de expansão da sociologia e antropologia social, especialmente no ano de 1952. Essa expansão pode ser explicada por diversos fatores, especialmente por decisões políticas que impunham objetivos de regeneração econômica e desenvolvimento social e pelo reconhecimento do papel das ciências sociais para alcançar tais objetivos nacionais. Vivia-se um momento de reconstrução, com incentivos ao crescimento e desenvolvimento do país, marcado pelo financiamento de instituições internacionais, a exemplo da Ford Foundation. 
Neste período houve também um crescimento de cientistas sociais, cujos trabaIhos focaram o desenvolvimento comunitário e as investigações políticas relevantes àquele contexto de desenvolvimento (Modi, 2010: 319).

No que diz respeito às abordagens teóricas deste período, o autor destaca que a sociologia na Índia desenvolveu-se, em larga medida, num ambiente de tensão entre a herança da antropologia social britânica, da sociologia canonizada nos Estados Unidos e da tradição intelectual marxista.

Na Índia, a despeito dessas tentativas de reconstrução e desenvolvimento social e econômico, cabe destacar que a passagem de uma sociedade baseada na agricultura para a indústria acabou acarretando o aumento desigualdades internas. Apesar do sucesso de alguns setores econômicos, bem como da expansão de uma classe média, os problemas básicos continuaram: aumento da pobreza urbana, surgimento de guetos e favelas. As consequências deste processo podem ser visualizadas até os dias atuais e precisam ser mais estudadas (Modi, 2010: 321).

Sujata Patel e Kushal Deb (2006: 45) trazem para o debate um dos temas que marcaram a história da sociologia indiana, o dilema entre os estudos rurais e urbanos. Os autores apontam que a sociologia na Índia tem sido historicamente dominada pelos estudos rurais e que, nos últimos dez anos, há uma mudança radical de direção com o crescente desenvolvimento dos estudos urbanos. Enquanto os estudos rurais se concentraram nas mudanças das dinâmicas de castas e classes como manifestações nas transformações das hierarquias locais / rurais e das divisões do trabalho devido a novos processos produtivos, os estudos urbanos têm focado na emergência de distintas identidades e padrões de interação social entre diferentes grupos sociais e novos formatos de ação coletiva. Neste contexto, o debate acerca da tradição e da modernidade continua sendo repetidamente revisitado. Destaca como temas dos estudos urbanos: o processo urbano contemporâneo, as metrópoles indianas, o espaço urbano, o Estado, as políticas, a ação coletiva e a cultura urbana (Patel \& Deb, 2011: 455).

Em um contexto mais recente, a despeito da posição da sociologia indiana no cenário global, Modi (2010: 321) aponta para novos temas e novas linhas de preocupação num contexto marcado pela globalização: temas como justiça social, meio ambiente e ecologia, questões de gênero, liberalização da economia, fome, direitos humanos.

Alerta para a necessidade de tomada de consciência das "mentes cativas" - referência a uma "síndrome" que operou na Índia - e que diz respeito à falha dos sociólogos indianos em conceder atenção aos temas mais importantes relacionados aos 
contextos locais. Para Modi (2010: 323), os sociólogos estão demonstrando mais consciência da persistência das desigualdades que operam em diferentes níveis na sociedade e destaca ainda o problema da linguagem como obstáculo às publicações. Os sociólogos trabalham a partir de suas línguas regionais e acabam sofrendo com a falta de jornais nos quais podem publicar e, mesmo que escrevam em inglês, há poucas possibilidades de serem publicados, fazendo com que bons trabalhos acabem não sendo conhecidos e reconhecidos para além dos contextos locais. O tema da linguagem também é abordado por Lardinois (2009) que argumenta que a língua inglesa permanece como língua comum para a elite indiana, muito embora, há novos estudantes que não falam inglês e que esperam uma educação que enfatize as línguas nacionais.

Esta dimensão expressa, sem dúvida, o quanto ainda há de pensamento colonizado na forma de produzir e também de divulgar o conhecimento: na medida em que há uma língua dominante, é possível perceber como práticas e saberes permanecem silenciados, tanto por não se expressarem na "língua dominante" como por esta epistemologia dominante sequer reconhecer sua existência.

\section{QUADRO 2}

SOCIOLOGIA INDIANA, PERÍOdOS E TEMAS

\begin{tabular}{|c|c|c|}
\hline Período & & Temas \\
\hline $\begin{array}{l}\text { Período } \\
\text { pré-Independência }\end{array}$ & $\begin{array}{l}\text { Etnicidad } \\
\text { Família, } \\
\text { Economi } \\
\text { Ihadora. } \\
\text { Condiçõe } \\
\text { Sistema } \\
\text { Castas, }\end{array}$ & $\begin{array}{l}\text { religião e cultura. } \\
\text { trutura de parentesco, grupos étnicos. } \\
\text { rural, problemas da terra, estudos populacionais e condições da classe traba- } \\
\text { de vida dos camponeses e da classe trabalhadora. } \\
\text { cial indiano. } \\
\text { samento, estratificação social, comunidades tribais, sociedade urbana e rural. }\end{array}$ \\
\hline \multirow{4}{*}{$\begin{array}{l}\text { Período } \\
\text { pós-Independência }\end{array}$} & \multicolumn{2}{|c|}{ Desenvolvimento comunitário e as investigações políticas. } \\
\hline & $\begin{array}{l}\text { Estudos } \\
\text { rurais }\end{array}$ & $\begin{array}{l}\text { Mudanças das dinâmicas de castas e classes como manifestações nas transfor- } \\
\text { mações das hierarquias locais/rurais e das divisões do trabalho devido a novos } \\
\text { processos produtivos. }\end{array}$ \\
\hline & $\begin{array}{l}\text { Estudos } \\
\text { urbanos }\end{array}$ & $\begin{array}{l}\text { Emergência de distintas identidades e padrões de interação social entre } \\
\text { diferentes grupos sociais e novos formatos de ação coletiva; o processo } \\
\text { urbano contemporâneo; as metrópoles indianas, espaço urbano, Estado, } \\
\text { políticas e ação coletiva e cultura urbana. }\end{array}$ \\
\hline & \multicolumn{2}{|c|}{ Tradição e modernidade. } \\
\hline $\begin{array}{l}\text { Contexto } \\
\text { contemporâneo }\end{array}$ & \multicolumn{2}{|c|}{$\begin{array}{l}\text { Globalização. } \\
\text { Desigualdade social. } \\
\text { Justiça social. } \\
\text { Meio ambiente. } \\
\text { Ecologia. } \\
\text { Questões de gênero. } \\
\text { Liberalização da economia. } \\
\text { Fome. } \\
\text { Direitos humanos. }\end{array}$} \\
\hline
\end{tabular}


Modi (2010) finaliza destacando a preocupação atual da Associação Indiana de Sociologia em estabelecer redes e parcerias em diferentes partes do mundo, citando associações na África do Sul e mesmo no Brasil.

Podemos sintetizar as linhas de pesquisa na sociologia indiana contemporânea tal como apresentadas acima, no Quadro 2.

\section{Pistas para a comparação entre as sociologias do Sul}

Neste início de século, o padrão de trabalho intelectual da sociologia, moldado pela construção de uma investigação teoricamente densa, empiricamente rigorosa e com orientação crítica, produz as análises necessárias para ajudar a refletir sobre os tempos sociais na América Latina, na Índia e na China.

Mudanças nas políticas públicas, mobilizações na sociedade civil, pujança nos movimentos sociais e processos de transculturações sugerem novidades importantes nas sociedades latino-americanas. Presenciamos processos de transformação orientados pelos valores da soberania e da independência, da equidade e da justiça social, da recusa da humilhação e da discriminação racial e cultural, princípios que estão disseminados nos processos micro e macrossociais de construção da dignidade humana.

O padrão de trabalho científico do sociólogo é composto por um imperativo de responsabilidade social, de respeito aos direitos humanos e de conduta acadêmica orientada pela justiça que leva o cientista social habilitado a respeitar tanto o mérito científico como a relevância social de sua pesquisa.

A linguagem informacional está permitindo a superação de antigas antinomias, pelo uso combinado e aplicado de diversos métodos quantitativos e qualitativos de pesquisa, configurando um padrão de trabalho científico que poderíamos denominar de sociologia informacional, cujos delineamentos precisos ainda estão em curso de fabricação pelos praticantes deste ofício. Saliente-se que o programa de análise do discurso e de imagens NVIVO10 apresenta versões em inglês, espanhol, português e mandarim.

As novas questões sociais em escala mundial constituem um vasto campo de interrogações à prática sociológica. Estão relacionadas, por um lado, à intensificação das relações de produção e de troca mercantil no espaço planetário; por outro, expressam a redução da capacidade regulatória dos Estados nacionais sobre o ordenamento do trabalho e da produção de mercadorias em seus territórios. Há, também, as possibilidades de comunicação abertas pelas tecnologias da informação 
que produzem transformações espaço-temporais nas relações sociais e conferem novos significados às formas de sociabilidade.

Se muitas são as possibilidades emancipatórias, há um universo de exclusão social e de segregação sócio espacial - por classes, gêneros, etnias, afinidades culturais, grupos etários - que exige uma teoria crítica da modernidade e da sociedade contemporânea.

Como a sociologia pode contribuir para responder aos questionamentos que desafiam a teoria sociológica e a sociedade atual?

A sociologia do Sul está inserida no espaço contemporâneo de conhecimento sociológico: um conhecimento sociológico internacional, investigando a realidade contemporânea, marcada por conflitualidades e dilaceramentos do tecido social e institucional, em configurações espaço-temporais que relacionam reciprocamente o local, o nacional e o mundial.

Ao reconhecer a prática sociológica como processo de construção de uma autoconsciência crítica da sociedade, não nos furtamos a idear possíveis históricos, em um difícil processo civilizatório que os cidadãos e as cidadãs, em um social mundializado, estão a imaginar e a construir.

Embora as diferentes tradições da sociologia remetam ao século XIX e ao início do século XX, houve momentos de ruptura epistemológica marcantes. Na Índia, a Independência acentua outro momento da sociologia. Na China, o marxismo dogmático provoca um grande hiato entre o período 1952-1980 e a retomada de uma "sociologia da transição". Na América Latina, a sociologia crítica dos anos 1960 foi fortemente abalada pelas ditaduras militares, mas retoma com ímpeto após os processos de democratização dos anos de 1990.

Capacidade criativa, manejo informacional e responsabilidade ética configuram desafios, densos e fecundos, para a ciência social. As práticas de análise social-complexa, informacional e transdisciplinar - podem ser definidas como saber do jovem século XXI orientado pela perspectiva de transformação do conhecimento e da sociedade na América Latina.

Temos um novo desafio intelectual: como construir as "epistemologias do Sul"? Do ponto de vista de uma "epistemologia do sul", tal qual propõe Boaventura de Sousa Santos, é interessante observar sob quais dimensões o colonialismo e esta epistemologia dominante vem sendo reatualizada, considerando-se a linguagem como forma de difundir este conhecimento. 
O objetivo deste texto foi de salientar alguns temas emergentes nas sociologias da América Latina, Índia e China, indicando a enorme tarefa que se vislumbra: como realizar um intercâmbio intelectual de conceitos, metodologias e hipóteses, de modo a começar um diálogo, infelizmente tão pouco realizado até agora? O início seria um mapa de questões sociológicas - como acima delineamos -, o qual revelou que as mencionadas sociedades fazem parte de uma Era de Mundialização de Conflitualidades, porém com algumas especificidades, pois os efeitos da globalização econômica são distintos assim como a atuação dos Estados nacionais é diversa. Há um enorme caminho a ser percorrido.

Estaríamos observando mais desdobramentos de uma epistemologia dominante que não apenas não reconhece a diversidade do saber, mas igualmente a sua forma de expressão? Continuamos à margem de uma ciência que ainda se constrói sob uma epistemologia dominante, que ainda reivindica um binarismo entre o "nós" e o "eles", cabendo a esta epistemologia a decisão sobre quais práticas e saberes se tornarão legítimos e inteligíveis? A discussão acerca de uma epistemologia dominante continua atual e pertinente, tal qual deve ser a reivindicação desse novo espaço de contestação, marcado pelas epistemologias do Sul. O diálogo com as sociologias indiana e chinesa parece ser um bom início para o estabelecimento de um novo patamar da internacionalização da sociologia crítica.

Os elementos do pensamento sociológico - investigação científica, compromisso político e imaginação sociológica - acompanhando as rupturas epistemológicas do tempo presente, constroem o pensamento crítico que acompanha os processos de transformação social contemporâneos. Nosso passo, será compartilhar o pensamento crítico e relacionar as experiências de novas utopias, em um processo de mundialização da sociologia contemporânea.

Abstract: This paper sets forth a reflection over the contributions that Latin American, Chinese and Indian sociologies may offer to the social thinking in the era of worldization of social conflictualities. We propose a multiple dialogue, based on the historicity of the social processes of building social thinking, regarding concepts, as well as the paths of knowledge construction, as having their own groundings that are neither universal, nor homogeneous. They reflect, instead, the recurrence of social struggles, the existence of local contradictions in heterogeneous contexts. We approximate Latin American, Chinese and Indian sociologies by following through this path of epistemological reconstruction under the concept of "epistemology of the South", as in Boaventura de Sousa Santos, and by promoting means to a dialogue amongst multiple practices and knowledges from those three parts of the world.

Key-words: epistemology, worldization, conflitualities, sociology, Latin America, Lantin-american sociology, China, Chinese sociology, India, Indian sociology, historicity. 


\section{Referências}

ALATAS, Syed Hussein. The autonomous, the universal and the future of sociology. Current Sociology, v. 54, n. 1, p. 7-23. London; Thousand Oaks, CA; New Delhi, Sage, Jan. 2006.

ARRIGHI, Giovanni. Adam Smith em Pekín: orígenes y fundamentos del siglo XXI. Madrid: Akal, 2007.

BAKKEN, Børge. Crime, punishment, and policing in China. New York: Rowman \& Littlefield, 2005.

BARAN, Paul. A economia política do desenvolvimento. Rio de Janeiro: Zahar, 1972.

BRICEÑO-LEÓN, R.; SONNTAG, Heinz R. (Ed.). Pueblo, época y desarrollo: la sociología de América Latina. Caracas: Nueva Sociedad, 1998.

BURAWOY, Michael; Chang, MAU-KUEI; FEI-YU HSIEH, Michelle (Orgs.). Facing an unequal world: challenges for a global sociology. Taipei: International Sociological Association; Academia Sinica, 2010.

CASTELLS, Manuel. A sociedade em rede. São Paulo: Paz e Terra, 1999.

CONSTITUTION OF THE PEOPLE'S REPUBLIC OF CHINA. Full text after amendment on March 14, 2004.

COSTA, Sérgio. Dois Atlânticos: teoria social, antirracismo, cosmopolitismo. Belo Horizonte: UFMG, 2006.

CHEN, Yingying. Rétrospective et réflexion sur l'enquete sociologique en Chine de 1980 à nos jours. In: ROULLEAU-BERGER, Laurence; GUO, Yuhua; LI, Peilin; LIU, Shiding. La nouvelle sociologie chinoise. Paris: Éditions du CNRS, 2008.

SHEN, Yuan. Ver le droit du citoyen: la défense des droits de propriétaires comme mouvement citoyen das la Chine contemporaine. In: ROULLEAU-BERGER, Laurence; GUO, Yuhua; LI, Peilin; LIU, Shiding. La nouvelle sociologie chinoise. Paris: Éditions du CNRS, 2008.

CHEVRIER, Yves; ROUX, Alain; XIAO-PLANES, Xiaohong (Éds.), Citadins et citoyens dans la Chine du XXème siècle. Essai d'histoire sociale. En hommage à Marie-Claire Bergère. Paris: Les Éditions de la Maison des Sciences de L'Homme, 2010.

CHUNG HO, Wing; PETRUS, N. G. Postsocialist future in a former socialist "Model community": public amnesia and multiple modernities in Shanghai: narrating the postsocialist future in a former socialist "Model community". Journal of Contemporary Ethnography, v. 37, p. 383, United Kingdom, Sage, 2008. 
DICTIONNAIRE DE LA CHINE CONTEMPORAINE. Paris: Armand Colin, 2006.

DWYER, Tom. Leadership challenges in transitional societies. Some reflections based on the Brazilian experience. International Conference on Youth Leadership in a Transformational Society. Anais... Pequim: China Youth University for Political Science, 2007.

A China e o Brasil. Mudanças e permanências e desafios para a sociologia brasileira. In: SCALON, Celi; RASIA, José Miguel; SALLAS, Ana Luisa Fayet (Orgs.). Mudanças e desafios sociológicos. Rio de Janeiro: 7 Letras; Sociedade Brasileira de Sociologia, 2012.

A China e os desafios das ciências sociais brasileiras no cenário do mundo em processo de globalização. In: RIBEIRO, Gustavo Lins; FERNANDES, Ana Maria; MARTINS, Carlos Benedito; TRAJANO FILHO, Wilson (Orgs.). As ciências sociais no mundo contemporâneo: revisões e prospecções. Brasília: Letras Livres e Editora da UnB, 2011.

EBREY, Patrícia Buckley. The Cambridge illustrated history of China. Cambridge: Cambridge University Press, 2010.

ELISSEEFF, Danielle. Hybride chinois: la quête de tous les possibles. Paris: Hazan, 2011.

FENBY, Jonathan. The Penguin history of modern China, the fall and rise of great power, 1850-2008. London: Penguin, 2009.

GRANET, Marcel. O pensamento chinês. Rio de Janeiro: Contraponto, 2004.

HARVEY, David. A condição pós-moderna. São Paulo: Loyola, 1993.

HOBSBAWM, Eric. O novo século. São Paulo: Companhia das Letras, 2000.

The age of extremes: a history of the world, 1914-1991. New York: Pantheon Books, 1994.

Era dos extremos: o breve século XX: 1914 - 1991. São Paulo: Paz e Terra, 1996.

Era dos extremos: o breve século XX: 1914 - 1991. São Paulo: Companhia das Letras, 2008.

IANNI, Octávio. A sociedade global. Rio de Janeiro: Civilização Brasileira, 1992.

JABBOUR, Elias Marco Khalil. Projeto nacional, desenvolvimento e socialismo de mercado na China de hoje. Tese (Doutorado em Geografia) - Faculdade de Filosofia, Letras e Ciências Humanas da Universidade de São Paulo, São Paulo, 2010. 
JING, Jun; SUN, Liping; SHEN, Yuan; GUO, Yuhua. Des chercheurs chinois réclament des réformes dans leur pays. Le Monde Diplomatique, Paris, Jul. 2011.

LAGERKVIST, Amanda. The future is here: media, memory, and futurity in Shanghai. Space and Culture, v. 13, p. 220, United Kingdom, Sage, 2010.

LARDINOIS, Roland. Taking a look at Indian sociology, 2009. Disponível em: <http:// www.reseau-asie.com/edito-en/reseau-asie-s-editorial/taking-a-look-at-indian-sociology-by-roland-lardinois-cnrs-senior-researcher-in-ceias-cnrs-ehess/>. Acesso em: 29 Ago. 2012.

LEE, Ching Kwan; SHEN, Yuan. China: the paradox and possibility of a public sociology of labor. Work and Occupations, v. 36, p. 110, United Kingdom, Sage, 2010.

LIEDKE, Enno. Sociologia e sociedade: Brasil e Argentina (1954-1984). Cadernos de Sociologia, n. 2, p. 5-50, Porto Alegre, Maio 1990.

LINSHAN, Hua; THIREAU, Isabelle. Les ruses de la démocratie. Protester en Chine. Paris: Seuil, 2010.

LI, Peilin; LI, Wei. O status econômico e as atitudes sociais dos trabalhadores migrantes na China. In: DWYER, Tom; VILLAS BOAS, Glaucia; SCALON, Celi. Consensos e controvérsias. Porto Alegre: Tomo, 2011.

LI, Peilin; GUO, Yuhua; LIU, Shiding. La sociologie chinoise face à la transition sociale. In: ROULLEAU-BERGER, Laurence; GUO, Yuhua; LI, Peilin; LIU, Shiding. La nouvelle sociologie chinoise. Paris: Éditions du CNRS, 2008.

LOPEZ, Felix G. Política e burocracia nos estados da Índia e do Brasil. Rev. Sociolog. Polit. [online], v.16, p. 69-92, 2008.

MENZIES, Gavin. 1421 - o ano em que a China descobriu o mundo. São Paulo: Bertrand Brasil, 2006.

MINISTÉRIO DA SEGURANÇA PÚBLICA DA CHINA <http://www.mps.gov.cn>.

MODI, Ishwar (Ed.). Modernization, globalization and social transformation. Jaipur: Rawat Publications, 2012.

MODI, Ishwar. Indian sociology faces the world. In BURAWOY, Michael; MAU-KUEI, Chang; FEI-YU HSIEH, Michelle (Eds.). Facing an unequal world: challenges for a global sociology. v. II. Taiwan: Institute of Sociology, Academia Sinica; Council of National Associations of the International Sociological Association, 2010.

MORIN, Edgar. Diário da China. Porto Alegre: Sulina, 2007; 
OOMMEN, T. K. Worldwide: a perspective from Índia. The nature of sociological research and practice. International Sociology, v. 3, n. 3, p. 309-312, 1988.

PATEL, Sujata; DEB, Kushal (Eds.). Urban studies (Oxford in India readings in social and cultural anthropology). New Delhi: Oxford University Press, 2006.

PEREIRA, Luiz. Ensaios de sociologia do desenvolvimento. São Paulo: Pioneira, 1970.

POSTER, M. The mode of information: poststructuralism and social context. Cambridge: Polity, 1990.

QUIJANO, Aníbal. Colonialidade do poder, eurocentrismo e América Latina. In: LANDER, Edgardo (Org.). A colonialidade do saber: eurocentrismo e ciências sociais. Buenos Aires: Consejo Latinoamericano de Ciencias Sociales (Clacso), 2005.

ROBERTS, J. História da China. Lisboa: Texto \& Grafia, 2006.

ROULLEAU-BERGER, Laurence; GUO, Yuhua; LI, Peilin; LIU, Shiding. La nouvelle sociologie chinoise. Paris: Éditions du CNRS, 2008.

SAID, Edward. Orientalismo. Lisboa: Cotovia, 2004.

SKOCPOL, Theda (Ed.). Vision and method in historical sociology. Cambridge: Cambridge University Press, 1984.

SOUSA SANTOS, Boaventura. A crítica da razão indolente. São Paulo: Cortez, 2000.

- A gramática do tempo: para uma nova cultura política. Porto: Afrontamento, 2006.

SOUSA SANTOS, Boaventura; MENESES, Maria Paula. Introdução. In: SOUSA SANTOS, Boaventura; MENESES, Maria Paula. Epistemologias do Sul. Coimbra: Edições Almedina, 2010.

SPENCE, Jonathan D. Em busca da China moderna: quatro séculos de História. São Paulo: Companhia das Letras, 1995.

TAVARES DOS SANTOS, José Vicente. Violências e conflitualidades. Porto Alegre: Tomo, 2009.

TREVISAN, Claudia. China. São Paulo: Contexto, 2009.

TWITCHETT, D. C. et alii. The Cambridge history of China. Cambridge: Cambridge University Press, 1978.

WANG, Dewei. The monster that is history: history, violence, and fictional writing in 
twentieth-century China. San Francisco: University of California Press, 2004.

WEBER, Max. Os Letrados Chineses. In: WEBER, Max. Ensaios de sociologia. Rio de Janeiro: Zahar, 1978.

WITTFOGEL, Karl. Oriental despotism: a comparative study of total power. New Haven: Yale University Press, 1957.

WOO, Margaret Y. K.; Gallagher, Mary E. (Eds.). Chinese justice: civil dispute resolution in contemporary China. New York: Cambridge University Press, 2011. 